\section{Gabriel Pedrosa}

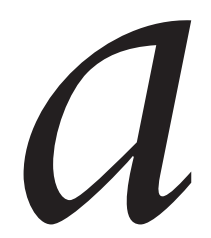

ERRÂNCIA COMO POTÊNCIA EM DOM QUIXOTE

\title{
RESUMO
}

A partir da recusa de Dom Quixote em buscar cortes ou cidades, explicitada em um diálogo com Sancho Pança no $21^{\circ}$ capítulo da primeira parte do livro de Cervantes, este artigo reflete sobre sua errância, como perambulação pelo descampado, mas também como comportamento não orientado por funções e como identidade em constante invenção. Esta reflexão, com as várias referências filosóficas e literárias que levanta, encontra não uma peculiaridade do cavaleiro manchego, mas uma tensão permanente em nossa cultura, propondo o Quixote como uma reversão do modo a que estamos habituados a lê-la.

Palavras-chave

Dom Quixote. Errância. Desconstrução. 


\section{WANDERING AS POTENCY IN DON QUIXOTE}

\section{ABstract}

From Don Quixote's refusal to seek courts or cities, made explicit in a dialogue with Sancho Panza in the twentieth-first chapter of the first part of Cervantes's book, this article reflects on his wandering, as a perambulation in the fields, but also as a non-functionoriented behavior and as an identity in constant invention. This reflection, with the various philosophical and literary references that it raises, finds not a peculiarity of the knight from la Mancha, but a permanent tension in our culture, proposing Don Quixote as a reversion of the way we are used to read it.

\section{KEYWORDS}

Don Quixote. Wandering. Deconstruction. 
1 No original: "He considerado cuán poco se gana y granjea de andar buscando estas aventuras que vuestra merced busca por estos desiertos y encrucijadas de caminos, donde, ya que se venzan y acaben las más peligrosas, no hay quien las vea ni sepa, y, así, se han de quedar en perpetuo silencio y en perjuicio de la intención de vuestra merced y de lo que ellas merecen".

2 "Parecia-me que enquanto eu Ihe falava, ele cuidadosamente analisava cada sentença que eu dizia; compreendia completamente seu significado não poderia contradizer sua irresistível conclusão; mas, ao mesmo tempo, alguma consideração primeira prevalecia para que ele respondesse como fazia" (MELVILLE, 1990, p. 11, tradução nossa), comportamento que perturba profundamente o patrão de Bartleby, "um homem que, de sua juventude em diante, tinha a profunda convicção de que o modo mais fácil de vida é o melhor" (MELVILLE, 1990, p. 3, tradução nossa).
Em meio a suas malandanças, "por caminhos sem caminho" (CERVANTES, 2011, p. 768, tradução nossa), diz Sancho Pança a seu amo:

Tenho considerado quão pouco se ganha e granjeia de andar buscando estas aventuras que vossa mercê busca por estes desertos e encruzilhadas de caminhos, onde, ainda que se vençam e acabem as mais perigosas, não há quem as veja nem saiba, e, assim, se hão de quedar em perpétuo silêncio e em prejuízo da intenção de vossa mercê e do que elas merecem (CERVANTES, 2011, p. 768, tradução nossa) ${ }^{1}$.

Parece-Ihe melhor buscar a corte de imperadores ou príncipes que estejam em guerras, em que o Quixote poderia mostrar seu valor, sendo, então, reconhecido e recompensado por seus senhores, além de ter suas façanhas registradas para a perpetuação de sua memória.

“- Não dizes mal, Sancho”, responde Dom Quixote (CERVANTES, 2011, p. 193, tradução nossa). O cavaleiro reconhece que seu escudeiro está com a razão, demonstra ter perfeita consciência de que, naquelas circunstâncias, sua proposta é a mais adequada ao fim declarado de suas aventuras e, no entanto, a despeito do bom resultado que prevê para ela, prefere não segui-la ${ }^{2}$.

Às vésperas da morte, ponto-final de uma vida desinteressante que permite ao prolixo narrador contá-la em dois parágrafos, Alonso Quijano decidiu abandonar os códigos que o sobredeterminavam, decidiu arrancar alegria - e alguma surpresa - ao pouco futuro que Ihe restava (e que, a seguir sendo Quijano, estava já previamente resolvido), decidiu, enfim, fazer-se o inventor de uma escritura estranha em lugar de apenas repetir a que supostamente lhe coubera, dando matéria, em poucos meses de perambulação, a mais de mil páginas a Cide Hamete Benengeli.

O fidalgo de aldeia abandonou a vida cuja única emoção era algum frango que acaso comia aos domingos (CERVANTES, 2011, p. 27) para se entregar à fantasia. Abandonou a existência que o enfadava imensamente, com seu fado definido, dado, como um conjunto de fatos já sabidos, apenas por esperar, de que já vinha se afastando para dedicar-se à leitura dos livros de cavalarias que o tiravam do abatimento em que seu cotidiano vazio o punha, da pasmaceira de estar preso a uma condição já por inteiro determinada.

"Milhares e milhares de pessoas fartaram-se da vida que levavam", diz Deleuze (2008, p. 340) sobre as cruzadas, em que vê uma fuga esquizofrênica só posteriormente apropriada e dominada pelo poder, pela Igreja e pela nobreza. Inspirada pelas cruzadas, a cavalaria andante passa a ser uma ideia de vida para o Quixote, uma alternativa à mediocridade que o carcomia desinteressadamente, sua desesperada tentativa de emprestar alguma grandeza a seus dias, não pela grandiosidade balofa e rançosa de castelos e princesas, 
${ }^{3}$ No original: "De mí sé decir que después que soy caballero andante soy valiente, comedido, liberal, bien criado, generoso, cortés, atrevido, blando, paciente, sufridor de trabajos, de prisiones, de encantos".

${ }^{4}$ Depois de perder o duelo para o Cavaleiro da Branca Lua, Dom Quixote abate-se imensamente, pois se vê obrigado a suspender sua escritura de cavalaria. A melancolia só não o toma por completo porque imagina uma nova possibilidade de vida que volta a animá-lo: tornar-se pastor (CERVANTES, 2011, p.

1.061). Suas máquinas desejantes são, então, reativadas, seu ímpeto vital volta a fluir, seu pensamento novamente dispara. Julgo este episódio de extraordinária importância, pois permite pensar que a paixão do Quixote é a invenção de sua escritura, não específica ou exclusivamente como cavaleiro andante. mas pelo imenso da empreitada, pelo terrível da invenção e pelo fato de que ela só poderia ser feita contra o funcionamento das pesadas máquinas deste mundo que ele queria outro, contra a gigantesca inércia desta "gigantocracia" e de seus intrincados sistemas de anulação e aprisionamento da escritura (CASTRO, 2002, v. 2, p. 385).

"Dom Quixote saiu em busca de um mundo fugidio, a fim de escapar do estável deixado para trás" (CASTRO, 2002, v. 2, p. 317, tradução nossa). E ao severo moralista que criticasse tal escritura como escapista, travestindo sua cômoda resignação de enfrentamento, caso quisesse ir além de um suficiente dar as costas, o Quixote poderia dizer que "ninguém jamais escreveu ou pintou, esculpiu, modelou, construiu, inventou a não ser para sair, realmente, do inferno" (ARTAUD, 2008, p. 272).

Para sair do inferno do mesmo, o Quixote inventa seu "novo modo de vida" (CERVANTES, 2011, p. 503-504, tradução nossa), inspirado pelas novelas de cavalaria (maior mérito que tais textos poderiam ter e principal crítica que o cônego de Toledo faz a eles). Fantasia-se, como os irmãos que Sancho surpreende em sua ronda noturna pela ilha Baratária, para ir "ver o mundo" e superar o desconsolo do encerramento em casa (CERVANTES, 2011, p. 925, tradução nossa). Mas, ao contrário deles, sob a fantasia do Quixote não há nada a esconder; não há identidade a preservar, apenas um personagem a construir, no vazio que há por trás de toda fantasia, de toda máscara, de toda palavra.

"Sua história poderia reduzir-se ao trânsito entre a irrealidade de sua vida cotidiana e a realidade de suas ficções" (PAZ, 1996, p. 208). Octavio Paz, no entanto, não fala sobre o Quixote. Seu comentário é sobre a heteronímia em Fernando Pessoa, sobre sua obra-paixão, em suas palavras, ou sobre sua errante escritura, nos termos deste texto, rumo ao desconhecido. A obra de Pessoa revela a iminência do desconhecido, usando novamente as palavras de Paz, que descobrimos ser quando - sinal de criação - nos encontramos.

Em sua criação, com sua recusa radical à banalidade, à "felicidade gorda da consciência tranquila" (NIETZSCHE, 2009b, p. 45), ao pronto em geral, à repetição do já feito e à consumação do já previsto, o Quixote efetivamente se faz outro. "De mim sei dizer que desde que sou cavaleiro andante sou valente, comedido, liberal, bem-educado, generoso, cortês, atrevido, brando, paciente, sofredor de trabalhos, de prisões, de encantos" (CERVANTES, 2011, p. 511 , tradução nossa) $)^{3}$.

E é por manter essa experiência de efetivamente inventar-se, de não apenas diluir o papel recebido nas coxias do teatro do mundo, pela alegria que isso lhe dá, pelo muito que aumenta sua potência de agir e sua capacidade de pensar, seguindo a bela definição de Espinosa (2009, p. 107), que o Quixote passará a lutar. Não se trata apenas de impor uma fantasia delirante ao mundo que a pretendia negar, de ser reconhecido cavaleiro ou de atingir os fins que tal condição sugeriria. Trata-se, antes, de conservar a possibilidade de ainda fantasiar ${ }^{4}$, de figurar outras formas de existência em que sua mente, embotada por uma rotina medíocre, e seu corpo, enfraquecido por seus muitos anos e doenças, passem a uma perfeição maior. Não são os supostos fins de suas andanças que o movem, mas a possibilidade de estar em movimento. 
${ }^{5}$ No original: "pelea en la guerra, vence al enemigo del rey, gana muchas ciudades, triunfa de muchas batallas, vuelve a la corte".
O Quixote sairá pela terceira vez, mesmo já se sabendo personagem de um famoso livro, abandonará a casa dos duques, onde é tratado como cavaleiro "verdadeiro, e não fantástico" (CERVANTES, 2011, p. 784, tradução nossa), evitará sua impossível Dulcinea e negará a que Sancho Ihe apresenta, bem como a qualquer das demais damas em cuja companhia se poderia precipitar um happy end.

Depois do fim, qualquer que fosse sua adjetivação, haveria ainda que seguir, e depois, e sempre, e de pouco serviria, então, ser imperador ou governador, sendo antes tais supostas conquistas impedimentos para o desdobrar de suas invenções, condenação a repetir o cotidiano de seus novos estados, esvaziando-o.

Os poetas conduzem seus heróis por milhares de dificuldades e perigos até o fim almejado; porém, assim que este é alcançado, de imediato deixam a cortina cair, pois a única coisa ainda a ser mostrada seria que o fim glorioso no qual o herói esperava encontrar a felicidade foi em realidade um ludíbrio, de modo que após atingi-lo não se encontra num estado melhor que o anterior. (SCHOPENHAUER, 2005, p. 412).

$\mathrm{Na}$ descrição do que se passaria caso seguissem a proposta de Sancho, Dom Quixote faz um resumo de uma novela de cavalaria tradicional, em que o herói, imediatamente reconhecido e festejado ao cruzar as portas de uma cidade, é recebido calorosamente pelo rei, em cujo palácio se hospeda, dando ocasião a que sua filha se enamore do cavaleiro. Esse sentimento é reforçado por suas façanhas, que culminarão na guerra que vencerá para seu novo senhor, depois do que se casará com a princesa, herdando o trono após a morte do rei, o que Ihe permite fazer muitas benesses a tantos quantos Ihe tenham ajudado, destacadamente a seu escudeiro, que ele fará que se case com uma alta donzela da corte, e todos serão felizes para sempre. Tudo narrado com o aborrecido dessa fatalidade mecânica.

Aqueles livros, que the consumiam dias e mais dias, com suas noites insones inclusas, em prazerosa e mesmo obcecante leitura, enredando-o em seus caudalosos volumes cheios de minúcias descritivas, volteios verbais e inextrincáveis razoamentos, vistos por seu fim, não davam senão as anódinas duas páginas e meia em que são resumidos. Os exércitos - que ante as manadas de ovelhas, mergulhados em fantasia, merecem belíssimas caracterizações, preparando o campo para uma não menos apaixonante batalha - neste diálogo, reduzidos a mero instrumento de chegar-se a coroas e ilhas que governar, não merecem mais que uma vaga alusão, num trecho de pouco mais de uma linha, em que a linguagem do Quixote, em outros momentos tão levantada e brilhante, subitamente se restringe a uma nota burocrática, por meio da qual se faz saber que o cavaleiro, depois de partir, "combate na guerra, vence o inimigo do rei, conquista muitas cidades, triunfa em muitas batalhas, volta à corte" (CERVANTES, 2011, p. 195, tradução nossa) ${ }^{5}$.

Eis a que se reduz uma escritura que se identifica por completo com uma função qualquer que possa assumir, com um ponto que Ihe possa dar fim. Eis porque é preciso, segundo o Quixote - razão que indica a Sancho para que não precipitem o fim de suas andanças - deixar-se no descampado. "É mister andar pelo mundo" (CERVANTES, 2011, p. 193, tradução nossa), seguir em busca de aventuras e façanhas. É preciso, primeiro, granjear fama, o que não é senão acumular sempre novas ocasiões para que sua escritura se crie, com 


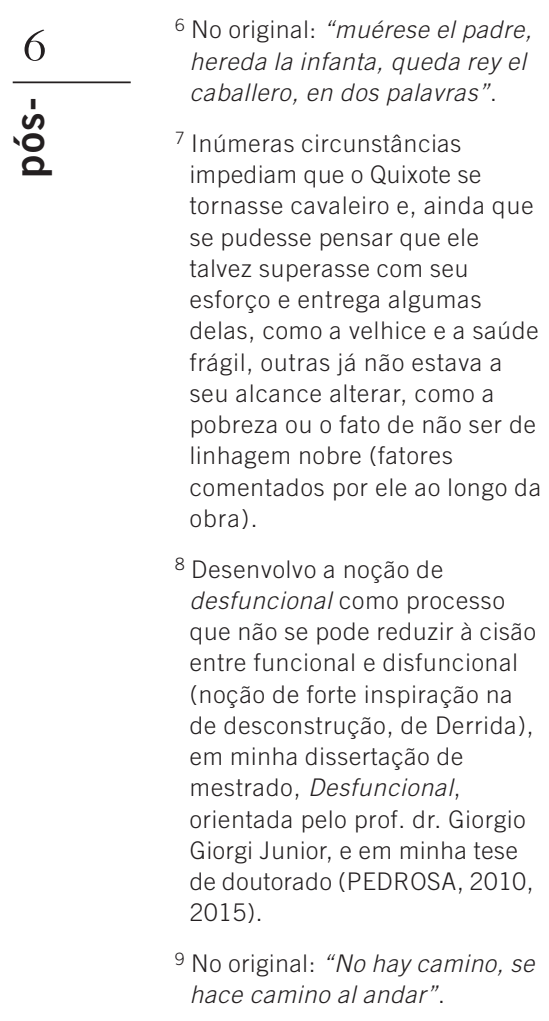

toda sua potência e brilho, pois é só aí que ela pode se dar, e é isso que o move, o que não se pode reduzir a uma ninharia como "morre o pai, herda a infanta, torna-se rei o cavaleiro, em duas palavras" (CERVANTES, 2011, p. 196, tradução nossa) ${ }^{6}$. A escritura é o que não cabe em duas palavras.

Abrir-se ao aberto da escritura, a seu devir. Toda a aventura quixotesca é uma louca empreitada contra os sistemas sociais e literários que o pretendem deter numa imagem prévia, num lugar já dado num quadro fixo de valores definidos. Sua errância não é decorrência aleatória de uma biblioteca reunida ao acaso, uma opção entre outras, mas a forma necessária para sua escritura não se estiolar na repetição estéril de uma certeza qualquer que se antecipe a sua ocorrência.

"É por ser inaugural, no sentido jovem deste termo, que a escritura é perigosa e angustiante. Não sabe aonde vai, nenhuma sabedoria a protege dessa precipitação essencial para o sentido que ela constitui e que é em primeiro lugar o seu futuro" (DERRIDA, 2002, p. 25). Mais que o futuro, seu devir, pois seu futuro poderia ser apenas, entre outros textos igualmente acabados, mofar nas páginas de uma antologia. O futuro projetado - da fama, do juízo final, da poupança ou da revolução -, como o passado resolvido em interpretações cristalizadas ou a verdade da presença do momento presente, são todas imagens de fixação e fechamento, de um tempo que só se faz como efeito de uma sucessão de quadros. Tempo que a errância nega.

Ao contrário do que se passa em outros livros do período, como no Lazarillo de Thormes ou no Guzmán de Alfarache (AVALLE-ARCE; RILEY, 1973, p. 48), a vida pregressa não condiciona a escritura do Quixote; sua vida não é o mero desdobramento de circunstâncias iniciais. Sua decisão extemporânea de tornarse cavaleiro rompe com qualquer linha que poderia já estar traçada. Mas tudo o que sobrevém a esse fiat rompe, por outro lado, com o próprio modelo que aparentemente inspira tal escritura, pois, ao contrário dos heróis das novelas de cavalarias tradicionais, como Amadíses ou Palmerins, ao afrontar um sem fim de interditos para a sagração de um cavaleiro ${ }^{7}$, o Quixote não caminha para se tornar, por força de seus atos, o nobre que sempre deveria ter sido. Antes, perambula sem rumo.

Nega as marcações passadas e futuras para deixar-se no tempo liso e desfuncional $^{8}$ do devir que, irredutível à regularidade e à causalidade cronológica, flui, presente como um rasgo no quadro presente, pelo qual se atravessa o movimento, indivisível, na constante promessa e na constante incerteza de novas mudanças, desordens. O atravessar da travessia, sua experiência, que em seu fazer-se abre os caminhos por que pode seguir. "Não há caminho, se faz o caminho ao andar" (MACHADO, 2005, p. 114, tradução nossa) $)^{9}$.

Sem fim nem começo, apenas meio, como queriam Deleuze e Guattari (2007, v. 4, p. 91), o Quixote executa "a invenção de se permanecer" na terceira margem. "Pondo perpétuo" (ROSA, 1985, p. 35), que nunca termina, que nunca está posto e que se opõe às margens, seus postos de observação, em que a vida é "só o demoramento" (ROSA, 1985, p. 33). É preciso confundir-se com a carne do tempo, deixar que o ir-se do rio corra no corpo, riscando o sem 
10 No original: "Expect poison from standing water".

11 Assim Deleuze (2006, p. 132) caracteriza o projeto filosófico de Nietzsche: "um modo de pensar, mas também um estilo de vida". fim da viagem, alheio às pontes e balsas que se fazem para chegar do outro lado e lá encontrar mais do mesmo.

Diz Heráclito, nas palavras de Nietzsche (2008, p. 56):

nada vejo senão o vir-a-ser. Não vos deixeis iludir! Se acreditais ver, em algum lugar, terra firme no mar do vir-a-ser e do perecer, isso se deve à vossa visão limitada, e não à essência das coisas. Utilizais nomes das coisas como se estas tivessem uma duração rígida: mas a própria correnteza, na qual entrais pela segunda vez, já não é mais a mesma que a da primeira vez.

Nessas águas faz-se o permanente fazer-se do Quixote, processo que nunca se acaba, em sua impossibilidade de estancamento, restituição de vida à vida e de fluxo às potências barradas pela razão funcionalista. "Espere veneno de águas paradas" (BLAKE, 2007, p. 26, tradução nossa) ${ }^{10}$.

A escritura não se detém em nenhuma verdade que encontre no caminho, nem se enrijece em nenhuma identificação que nele se faça. "Heráclito terá eternamente razão ao afirmar que o ser é uma ficção vazia. O mundo 'aparente' é o único: o 'mundo verdadeiro' é apenas um acréscimo mentiroso"

(NIETZSCHE, 2009b, p. 35). Todo o pensamento (e toda escritura, acrescentamos) é um devir, afirmam Deleuze e Guattari (2007, v. 5, p. 50), uma produção, o traçado de seu curso, não a expressão de um pensado que Ihe é anterior. Há, pois, que permitir que ele se faça, que não seja feito de fora, evitar que regras alheias o venham fechar, permitir que erre. "Pensar é essencialmente errar" (PESSOA, 2001, p. 129).

Em seus aforismos vitais, que são também anedotas do pensamento ${ }^{11}$, 0 Quixote dá vazão às potências de sua escritura, porque não Ihe fixa uma imagem de chegada, ou uma rota por seguir. "Se Dom Quixote houvesse traçado um itinerário, sua figura se teria desfeito" (CASTRO, 2002, v. 1, p. 77, tradução nossa). Articula, em suas aventuras, a vadiagem sem planos de suas andanças à errância de um humano que, em seu "desabrigo transcendental" (LUKÁCS, 2003, p. 37), livre de qualquer obrigação de unidade ou totalidade, mas também desprotegido dos sistemas de pensamento que aí o reconfortariam, vê-se às voltas com a tarefa de se criar e criar as condições em que possa existir (LUKÁCS, 2003, p. 84).

Na passagem do mundo clássico para o moderno, em cujo vinco desliza o Quixote, a unidade e a homogeneidade do mundo e dos homens se esfacela e, com isso, um tem de inventar-se, a despeito da massa de que difere, do mundo que o estranha. 0 herói do romance tateia, vacila, erra. Já não há sinal dos deuses que poderiam conduzi-lo e os homens que ele encontra pelo caminho não apenas também estão perdidos como muitas vezes o ignoram. Está sozinho num mundo que, para ele, perdeu a capacidade de fazer sentido ou, ao menos, de abrigar os já feitos. Onde quer que esteja, está fora de lugar. Apenas os homens mortos, as línguas mortas, podem ter lugar; tudo que ainda vive precisa inventar-se um lugar, não para habitar, mas para abandonar. Inventar-se em meio às circunstâncias que o envolvem para negá-las, mudá-las, fazê-las outras.

O que move o Quixote é essa abertura que encontra em si, a incompletude de sua figura, de sua história. Esta é sua obra, o sentido da escritura a que ele se 


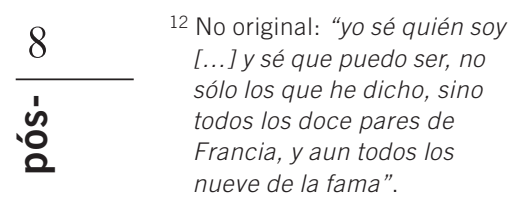

propõe entregar: construir sentidos, desbaratar o pronto de um mundo caduco que a quer deter, que pretende estancar seu fluxo ou, ao menos, domesticá-lo. Em sua primeira saída, ainda um pouco duvidoso de ser Don Quijote de la Mancha e um tanto atordoado pela surra que levou dos mercadores toledanos, ele afirma ser Valdovinos, depois Abindarráez e, diante das negativas de seu vizinho de povoado que insiste em chamá-lo Quijana, diz: “- Eu sei quem sou [...] e sei que posso ser, não apenas os que disse, mas todos os doze pares de França, e ainda todos os nove da fama" (CERVANTES, 2011, p. 58, tradução nossa) $)^{12}$.

Saber quem se é não é haver se encontrado, haver encontrado algo como uma verdade ou essência, mas ter construído a insuficiência de ser o que quer que seja de estanque, fidalgo ou cavaleiro, louco ou são (lavrador, escudeiro ou governador, para Sancho, em quem também se vê essa transformação). Não é ter encontrado, como quem cava um chão de palavras, um dado que se estaria condenado a representar, mas ter inventado novos modos de fazer seu desejo impulsionar sua escritura, na "multiplicidade pura, [...] irredutível à unidade" (DELEUZE; GUATTARI, 2004, p. 45) da produção desejante.

Não há um si mesmo por encontrar e conhecer, pois tudo está sempre ainda por fazer. Há um novo, outro si, como potência, a "alma como multiplicidade do sujeito" (NIETZSCHE, 2009a, p. 35), por inventar-se, no curso da escritura, do tempo, que impede qualquer sedimentação ou permanência passivas. "De um extremo a outro, o eu é como que atravessado por uma rachadura: ele é rachado pela forma pura e vazia do tempo" (DELEUZE, 2009, p. 133).

Eu tem de ser um outro, como queria Rimbaud, um outro que diga, em mim, na língua do outro, com os pensamentos de outros, a impossibilidade de fechar-se em uma imagem. É só o outro que pode me dizer, chamar-me eu, recortar no contínuo do texto este objeto eu. Não fôssemos povoados por muitos: homens, mulheres, pássaros, baleias, velhos, crianças, cactos, avencas, bicos-de-papagaio, nuvens, dunas, músicos, estivadores, burocratas, dançarinos, loucos, viajantes, degredados, vagabundos, governadores, andantes, cavaleiros, sem ser nenhum, não teríamos como dizer eu. "Sob o eu que age há pequenos eus que contemplam e que tornam possíveis a ação e o sujeito ativo. Não dizemos 'eu' a não ser por estas mil testemunhas que contemplam em nós; é sempre um terceiro que diz eu” (DELEUZE, 2009, p. 118). Eu é apenas a possibilidade de um ponto em que algumas dessas escrituras que se atravessam, que me atravessam e assim me fazem, continuem se produzindo; pontuação do texto que me inventa e carrega.

Por isso, há que seguir, fazer-se, tornar-se o instável e provisório que se é, em processo. Em sua escritura louca, o Quixote sai de si e, por mais que retorne à casa e ao nome Alonso Quijano, por força de suas invenções, já não pode voltar à mesmice de seu si de fidalgo, a sua vida banal e ensimesmada. Fez-se outros, tem de fazer-se ainda outros, o sempre outro que se é, o si-outro, figura que atravessa os fluxos, os textos, que os recorta e reconfigura, mas que também se muda, afetada por eles, nessa travessia.

É preciso desencaminhar-se, perder-se completamente. Abandonar qualquer certeza, especialmente a certeza de si, do eu, do penso, do existo, para que o pensamento e a existência possam se fazer. Todos os caminhos levam a algum lugar, desde que se ande o bastante, diz o gato de Chesire a Alice (CARROLL, 
13 "Ao regressar da viagem, escreveu a introdução de Poisson soluble [...]. A viagem, empreendida sem escopo e sem meta, tinha-se transformado na experimentação de uma forma de escrita automática no espaço real, uma errância literário-campestre impressa diretamente no mapa de um território mental" (CARERI, 2013, p. 78).

14 No original: "Les vrais voyageurs sont ceux-là seuls qui partent pour partir".

15 No original: "Sali de mi patria, empeñé mi hacienda, dejé mi regalo y entregueme en los brazos de la fortuna, que me llevasen donde más fuese servida".

16 "Mas, agora, estou condenado a errar, envolvido em uma empreitada distante, todos os dias perco o gosto pelo clima e pelas maneiras de viver e mesmo pela língua da Europa" (RIMBAUD, 2001, p. 33, tradução nossa).

17 No original: "Je suis trop habitué à la vie errante et gratuite; enfin, je n'ai pas de position. Je dois donc passer le reste de mes jours errant dans les fatigues et les privations, avec l'unique perspective de mourir à la peine".

18 No original: "Pour moi, je compte quitter prochainement cette ville-ci pour aller trafiquer dans l'inconn".
1998, p. 56). Todos os caminhos levam, desde que se ande. A questão da escritura é poder andar, como a picada dos Nhambiquaras na mata (DERRIDA, 2004, p. 133), ou a perambulação de Bréton ${ }^{13}$, o processo, como texto ou vida, como poema ou viagem. "Os verdadeiros viajantes são somente aqueles que partem por partir" (BAUDELAIRE, 1985, p. 442, tradução nossa) ${ }^{14}$.

O Quixote é um verdadeiro viajante, não apenas por não ter destinos definidos, mas também - e talvez principalmente - pelo abandono que sua partida implica. "Saí de minha terra, empenhei meus bens, deixei meu regalo e me entreguei aos braços da fortuna, que me levasse aonde melhor Ihe servisse" (CERVANTES, 2011, p. 662, tradução nossa) ${ }^{15}$. Num trecho em que compara seu caminhante com os cavaleiros andantes de outrora, por seu espírito de heroico desprendimento, Thoreau (2012, p. 49) escreve: "se você estiver pronto para deixar pai e mãe, irmão e irmã, mulher, filhos e amigos, e nunca mais os ver - se tiver pagado suas dívidas, feito seu testamento, deixado em ordem todos os seus negócios e for um homem livre, então você estará pronto para uma caminhada".

Já não há casa a que voltar, nem uma nova por encontrar, apenas o anseio por uma errância absoluta, um reconhecimento, como o de Rimbaud, de estar condenado a errar ${ }^{16}$, a estranhar-se em casa, a desaclimatar-se. "Estou bastante habituado à vida errante e gratuita; enfim, já não tenho lugar. Devo, portanto, passar o resto de meus dias errando entre fadigas e privações, com a única perspectiva de morrer de cansaço." (RIMBAUD, 2001, p. 61, tradução nossa) ${ }^{17}$. Não caber em casa, não se reconhecer na vida que se tem, não pertencer à vila em que se mora. 0 vilarejo do Quixote nunca é nomeado na obra, pois o cavaleiro não é de lá, é da Mancha, de toda a região por onde perambula, seu meio, sua vastidão.

"Deixem-me viver onde quiser, deste lado está a cidade, do outro, a vastidão, e estou deixando a cidade cada vez mais e me retirando para o ermo" (THOREAU, 2012, p. 64). Na cidade, "macaca da corte" (ELIAS, 2001, p. 62), imperam os códigos. Os desvios, vitais, aí não têm lugar. "Os loucos tinham então uma existência facilmente errante. As cidades escorraçavam-nos de seus muros; deixava-se que corressem pelos campos distantes" (FOUCAULT, 2007, p. 9). Apenas fora das cidades a aventura tresloucada do Quixote pode transcorrer, só aí o incerto de sua errância é possível. "Por mim, conto com deixar em breve esta cidade para ir traficar no desconhecido" (RIMBAUD, 2001, p. 18, tradução nossa) ${ }^{18}$.

Em Barcelona, onde a radical inadequação de sua vida incerta e vadia ao cotidiano das cidades se faz patente a cada evento, Dom Quixote visita uma tipografia. Nas cidades os livros são impressos, e eles contam histórias acabadas. Se Ginés de Pasamonte não pode fechar sua autobiografia porque ainda vive (CERVANTES, 2011, p. 206), o Quixote talvez intua que deve evitar as cidades para não antecipar a conclusão de sua narrativa.

No meio urbano, a vida se organiza, cria sistemas, fixa valores, estabiliza-se. Nele, os caminhos já estão traçados, em seus calçamentos, em suas ruas com suas casas numeradas, em suas placas indicando onde o comércio, onde cada serviço, onde os encontros. Para lá Sancho quer ir e lá se passa o final feliz$$
\text { dans linconsus }
$$ 
que o Quixote prevê e prefere evitar. Na cidade, tal previsibilidade é possível, pois seus muros e guias constrangem e moldam o futuro, homogeneízam o espaço, o tempo e todas as possibilidades do que neles se possa dar. Do espaço controlado da cidade, espaço de produção e verificação do mesmo, espaço de reprodução, sabe-se o que se deve esperar.

Não espanta, pois, que séculos adiante, na ponta dessa lança, a cidade venha a ser chamada inteligente quando se mostrar eficiente na anulação de qualquer eventualidade, qualquer alteridade, qualquer coisa que se passe fora do programado. A cidade será inteligente se lograr antecipar-se à vida para impedir seus acontecimentos, pois sua inteligência não é senão o controle sobre seus habitantes, sobre a potência inventiva de suas escrituras, sobre suas incontroláveis inteligências.

A firme determinação do engenhoso cavaleiro em não realizar aquilo que dele se espera implica, dessa forma, dar as costas a esse espaço de sobredeterminação da escritura e rumar ao desconhecido, à ausência de referências do descampado, aos estranhos e insuspeitos sucessos que podem se fazer um lugar na imensidão. Aí, a abertura do espaço é, mais que a inexistência de barreiras físicas, a variedade e a imprevisibilidade do que possa acontecer. "Talvez seja preciso dizer que todo progresso se faz por e no espaço estriado, mas é no espaço liso que se produz todo devir" (DELEUZE; GUATTARI, 2007, v. 5, p. 195). Os campos por onde erra o Quixote são o espaço liso, espaço que se ocupa sem medir (em oposição ao inventário da ocupação contábil do espaço estriado). Espaço desmesurado, sem centro, sem hierarquia interna, espaço da experiência que se faz no acontecer da experiência e onde "a vida reconstitui seus desafios, afronta novos obstáculos, inventa novos andamentos" (DELEUZE; GUATTARI, 2007, v. 5, p. 214).

Inversamente, "a cidade é o espaço estriado por excelência" (DELEUZE; GUATTARI, 2007, v. 5, p. 188), onde sempre se está em relação a um centro dado, a um marco zero, a sistemas de marcação e valor. No espaço estriado não há errância, pois ele reduz a deambulação a uma soma de passos, de estágios, aprisionados numa grelha anterior e alheia a seu curso. O espaço liso desliza sob os pés, sob os cascos, e se reorganiza, num movimento infinito, em função dos movimentos a que dá ocasião; espaço que erra sob o errante que o refunda a cada passo, a cada hesitação ou tropeço.

Saturada de significados, a cidade impede a invenção de sentidos, a continuidade da criação quixotesca. Nela, todo e cada elemento de qualquer escritura deverá ser previamente fixado, de acordo com suas normas, suas tradições e com a posição social de cada enunciador.

Com a etiqueta, a sociedade de corte procede a sua autoapresentação, cada pessoa singular distinguindo-se de cada uma das outras, e todas elas se distinguindo conjuntamente em relação aos estranhos ao grupo, de modo que cada uma em particular e todas juntas preservam sua existência como um valor autossuficiente. (ELIAS, 2001, p. 120).

Norbet Elias (2001) descreve a conduta regida pelos códigos de etiqueta, mas soa como Saussure descrevendo seu xadrez linguístico e a ambição de fixar valores aí implicada. 
19 No original: "Volveos a vuestra casa y criad vuestros hijos, si los tenéis, y curad de vuestra hacienda, y dejad de andar vagando por el mundo".
Há que manter o código, pois ele garante não apenas a comunicação da posição de cada indivíduo, mas as possibilidades, deveres e interdições de sua escritura. 0 código garante o bom funcionamento da sociedade e assim garante a manutenção da ordem, com o que são mantidos os significados da estratificação social, que permitem que o código funcione e se perpetue. Todo código, como observa Nietzsche sobre o de Manu (2011, p. 110), não cria nada, encerra.

Marcação de lugares fixos na estrutura, correta distribuição de valores a partir da correta representação do papel dado, cenário para uma peça já escrita, o modo ordenador de composição das cidades e cortes se opõe ao conflituoso da invenção quixotesca. Elas cobrarão de Quijano ser Quijano, fidalgo de aldeia, velhote e remediado, não tolerando seu extravagante e despropositado personagem.

Por essa razão, como observa Américo Castro (2002, p. 364, tradução nossa), Cervantes

Concentrou suas preferências sobre os alijados da vida da cidade, voluntária ou forçadamente [...] e os fez vagar pelo ar livre dos campos, ou demorar-se em estalagens, como num ponto de momentâneo repouso para suas existências inquietas ou incitadas. O ambiente doméstico e sedentário, as realidades quietas e imóveis, ou se eludem, ou aparecem como leve pano de fundo [...] sobre o qual projetar o contínuo movimento do viver.

No entanto, mesmo no descampado, a errância, seu modo estrangeiro de estar no mundo, é uma construção. Os campos de Montiel não são o lugar natural para as aventuras quixotescas, pois uma tal escritura não tem lugar natural, não está prevista nem tem cabimento onde quer que seja. Ela tem de forçar sua entrada no mundo que a estranha. E, então, cumpre observar que mesmo um ambiente urbano poderia dar lugar a uma vida errante (marginal, certamente).

E se a cidade ainda pode abrigar espaços lisos e devires em caminhos tornados equívocos por um modo nômade de habitá-la, como lembram Deleuze e Guattari (2007, v. 5, p. 185), a casa, com suas paredes tumulares e os retratos mortuários aí pendentes, detém qualquer possibilidade de escritura. Na casa o fechamento é total e se encerra qualquer possibilidade de alguém inventar-se outro daquele que ela aprisiona - para ser levado de volta à casa, como numa preparação, o Quixote tem de ser enjaulado (CERVANTES, 2011, p. 498). Não faltam no livro "espíritos minguados", como os chamou Unamuno (2005, p. 174, tradução nossa), exortando o Quixote a abandonar-se, a resignar-se a retomar seu antigo papel, a ficar em casa: "voltai a vossa casa e criai vossos filhos, se os tendes, e cuidai de vossas posses, e deixai de andar vagando pelo mundo" (CERVANTES, 2011, p. 792, tradução nossa) ${ }^{19}$.

Na comparação entre as duas partes da obra de Cervantes nota-se como, na segunda, o Quixote vacila, duvida de sua fantasia e mesmo se desquixotiza por vezes, talvez em função de sua maior permanência em casas: casas de nobres, onde encenações menores e controladas repetem textos já sabidos, buscando preencher um tempo sem sentido para tentar fazê-lo passar - como a casa dos duques e a de Antonio Moreno, em Barcelona; ou a casa de Don Diego de 


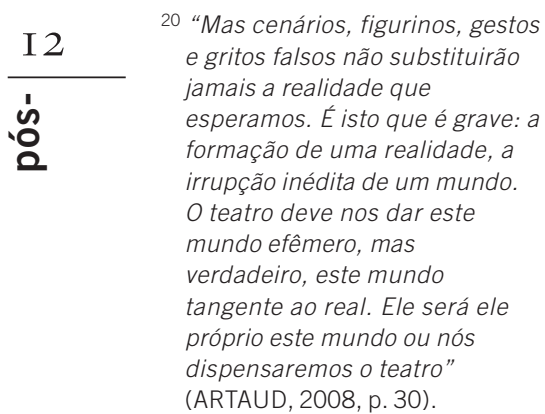

"Mas cenários, figurinos, gestos gritos falsos não substituirão esperamos. É isto que é grave: a ormação de uma realidade, a (leção inédita de um mundo. mundo efêmero, mas verdadeiro, este mundo (ARTAUD, 2008, p. 30)
Miranda, cavaleiro exemplar, fixado em sua exemplaridade, morto em sua perfeição, o que se evidencia no silêncio sepulcral de sua morada (CERVANTES, 2011, p. 684).

A ação se fecha, perde a abertura caótica do descampado, com seus inúmeros e heterogêneos episódios. das aventuras imprevistas e disparatadas do primeiro livro, passamos aos julgamentos do Quixote ou a um teatro anêmico, embora aparatoso (ou porque aparatoso, diria Artaud) ${ }^{20}$. Do inesperado e fragmentado conjunto de acontecimentos, a narrativa passa ao encadeamento causal e habitual dos eventos da vida doméstica, domesticada.

Dom Quixote rejeita a proposta de Sancho porque vê, em seu funcionalismo, uma tentativa de precipitar o fim de suas aventuras. Coloca-se, nesse diálogo, que se passa quando o escudeiro ainda não aderiu à fantasia do amo (o que ocorrerá depois, tornando-se evidente, por exemplo, em seu abandono do tão sonhado governo para voltar à errância), uma tensão que atravessa todo o livro, na disputa entre abertura e fechamento na escritura do cavaleiro manchego.

O impulso vital do desejo a formula e mantém, a despeito de todas as suas supostas condicionantes (a tabela de logaritmos que pretende calcular e decidir a vida do homem do subsolo), fazendo que sua escritura precise de permanentemente afirmar-se como criação. As ações loucas do cavaleiro talvez sejam uma forma de perguntar: "não será melhor dar um pontapé em toda esta sensatez unicamente a fim de que todos esses logaritmos vão para o diabo, e para que possamos mais uma vez viver de acordo com a nossa estúpida vontade?" (DOSTOIÉVSKI, 2004, p. 38). Dom Quixote quer sempre abrir sua sequência ao aberto de suas possibilidades indefinidas.

Todos os seus interlocutores, no entanto, seja por buscarem nas coordenadas passadas as determinações que constrangeriam seu presente, seja por tentarem moldá-lo de forma a redundar num futuro igualmente definido, esforçam-se, todo o tempo, por negar essa abertura, encerrando sua narrativa numa linearidade que não apenas a mutila como a nega, por identificá-la com uma imagem já feita (e não com um movimento de fazer). Na arqueologia do fidalgo Quijano ou na teleologia do imperador Quixote, em sua casa ou na corte que salvará, não tem lugar o insuspeitado de suas andanças.

Evitar as cidades e suas casas, seus muros, seus códigos, seus limites - errar, em uma palavra - é, pois, o único modo possível de o Quixote seguir. Seu lugar é o descampado, sem contornos nem valores precisos, onde o mais cotidiano moinho bem pode fazer a figura de gigante, na ausência de demarcações de seu fundo alisado. Seu tempo é o contínuo e incerto movimento do devir, e sua única identidade possível é a fugidia imagem sempre oscilante entre os fidalgos que abandonou e os cavaleiros que não pode ser, interstício onde suas muitas outras figuras se encontram.

A errância, no Quixote, supera a negatividade e a secundariedade a que fomos habituados a ver no termo, mostrando-se, em toda a sua imensa potência, como um modo da escritura de invenção. Todo o finalismo, o utilitarismo, o funcionalismo, toda a linearização temporal e a demarcação espacial que the 
dá suporte, o modo todo, enfim, de a escritura logocêntrica ocidental operar é abalado por essa reversão.

Algo se abriu nos vastos campos da Mancha, algo que aqui ressoa, que corre no rio de Heráclito, Nietzsche e Deleuze, nas águas de Rosa e Blake, que fala nas máscaras de Pessoa e no teatro sem máscaras de Artaud, que perambula com a Alice, de Carroll, com o caminhante de Antonio Machado, com Baudelaire, Bréton, Rimbaud, Thoreau. Uma dúvida, talvez (como as do homem do subsolo ou de Bartleby), que não contém princípio de método nem fundamento de sua anulação. Uma dúvida sem certeza que Ihe venha encerrar. E ela se move. Não há traçado prévio sobre o qual projetar os rastros da perambulação realizada (esmaecida pelo privilégio que aprendemos a dar a esse ideado fantasma), não há que realizá-la sobre qualquer esquema dado, nem prendê-la a qualquer ponto, de partida ou chegada. Parte da permanente vitalidade do Quixote talvez se deva à permanente perplexidade com que nossa cultura lê sua recusa à proposta de Sancho, desconcertante desafio aos nossos modos de pensar e agir.

\section{REFERÊNCIAS}

ARTAUD, Antonin. O teatro e seu duplo. São Paulo: Max Limonad, 1984

ARTAUD, Antonin. Linguagem e vida. São Paulo: Perspectiva, 2008.

AVALLE-ARCE, Juan Bautista; RILEY, Edward (org.). Suma cervantina. London: Tamesis books, 1973.

BAUDELAIRE, Charles. As flores do mal. Rio de Janeiro: Nova Fronteira, 1985.

BLAKE, William. O matrimônio do céu e do inferno. São Paulo: Iluminuras, 2007.

CARERI, Francesco. Walkscapes. São Paulo: GG, 2013.

CARROLL, Lewis. Alice's adventures in wonderland and through the looking-glass. London: Penguin, 1998.

CASTRO, Américo. Obra reunida. Madri: Trotta, 2002. 2 v.

CERVANTES, Miguel de. Don Quijote de la Mancha. Madrid: Punto de Lectura, 2011.

DELEUZE, Gilles. Lógica do sentido. São Paulo: Perspectiva, 2006.

DELEUZE, Gilles. A ilha deserta. São Paulo: lluminuras, 2008.

DELEUZE, Gilles. Diferença e repetição. São Paulo: Graal, 2009.

DELEUZE, Gilles; GUATTARI, Félix. O anti-édipo: capitalismo e esquizofrenia. Lisboa: Assírio e Alvim, 2004.

DELEUZE, Gilles; GUATTARI, Félix. Mil platôs. São Paulo: Editora 34, 2007. 5 v.

DERRIDA, Jacques. A escritura e a diferença. São Paulo: Perspectiva, 2002.

DERRIDA, Jacques. Gramatologia. São Paulo: Perspectiva, 2004.

DOSTOIÉVSKI, Fiódor. Memórias do subsolo. São Paulo: Editora 34, 2004.

ELIAS, Norbert. A sociedade de corte. Rio de Janeiro: Zahar, 2001.

ESPINOSA, Baruch de. Ética. Belo Horizonte: Autêntica, 2009.

FOUCAULT, Michel. História da loucura. São Paulo: Perspectiva, 2007.

LUKÁCS, Georg. Teoria do romance. São Paulo: Editora 34, 2003.

MACHADO, Antonio. Poesía. Madrid: Alianza editorial, 2005.

MELVILLE, Herman. Bartleby. New York: Dover, 1990.

NIETZSCHE, Friedrich. A filosofia na era trágica dos gregos. São Paulo: Hedra, 2008.

NIETZSCHE, Friedrich. Além do bem e do mal. Porto Alegre: L\&PM, 2009a. 
NIETZSCHE, Friedrich. Crepúsculo dos ídolos. Porto Alegre: L\&PM, 2009b.

NIETZSCHE, Friedrich. O anticristo. Porto Alegre: L\&PM, 2011.

PAZ, Octavio. Signos em rotação. São Paulo: Perspectiva, 1996.

PEDROSA, Gabriel. Desfuncional. 2010. Dissertação (Mestrado em Arquitetura e Urbanismo) Faculdade de Arquitetura e Urbanismo, Universidade de São Paulo, São Paulo, 2010.

PEDROSA, Gabriel. Quixote, andante poesia. 2015. Tese (Doutorado em Arquitetura e Urbanismo) - Faculdade de Arquitetura e Urbanismo, Universidade de São Paulo, São Paulo, 2015.

PESSOA, Fernando. Poesia: Alberto Caeiro. São Paulo: Companhia das Letras, 2001.

RIMBAUD, Arthur. Lettres du Harar. Paris: Mille et Une Nuits, 2001.

ROSA, João Guimarães. Primeiras estórias. Rio de Janeiro: Nova Fronteira, 1985.

SCHOPENHAUER, Arthur. O mundo como vontade e como representação. São Paulo: Unesp, 2005.

THOREAU, Henry David. Caminhando. Rio de janeiro: José Olympio, 2012.

UNAMUNO, Miguel de. Vida de Don Quijote y Sancho. Madrid: Alianza Editorial, 2005.

\section{Nota do Autor}

Este artigo é parte de minha pesquisa de pós-doutorado no Programa de Estudos Pós-Graduados em Comunicação e Semiótica da Pontifícia Universidade Católica de São Paulo, supervisionado pela profa. dra. Lucrecia Ferrara, e decorre de trabalho apresentado ao colóquio Cidade \& alma, perspectivas, realizado na Faculdade de Arquitetura e Urbanismo da Universidade de São Paulo, em outubro de 2017, e de minha tese de doutorado, Quijote, andante poesia, orientada pelo prof. dr. Luís Antônio Jorge.

\section{Nota do Editor}

Data de submissão: 26/06/2018

Aprovação: 21/11/2019

Revisão: Tikinet

\section{Gabriel Pedrosa}

Pontifícia Universidade Católica de São Paulo. Programa de Estudos PósGraduados em Comunicação e Semiótica. Rua Ministro de Godoy, 969, 4 andar, sala 4A-08, Perdizes - 05015-901 - São Paulo - SP

ORCID: http://orcid.org/0000-0002-5061-249X

gpedrosap@gmail.com 